\title{
CORRECTION
}

\section{Correction to: The IRAK-ERK-p67phox-Nox-2 axis mediates TLR4, 2-induced ROS production for IL-1 $\beta$ transcription and processing in monocytes}

Ankita Singh ${ }^{1}$, Vishal Singh ${ }^{1}$, Rajiv L. Tiwari ${ }^{1}$, Tulika Chandra ${ }^{2}$, Ashutosh Kumar ${ }^{3}$, Madhu Dikshit ${ }^{1}$ and Manoj K. Barthwal ${ }^{1}$

Cellular \& Molecular Immunology (2019) 16:946; https://doi.org/10.1038/s41423-019-0286-1

Correction to: Cellular and Molecular Immunology https://doi.org/ 10.1038/cmi.2015.62.

In this article, published online on 31 August 2015, there was an unintended error during image processing of Fig. $2 \mathrm{~b}$ leading to pasting of total ERK and $\beta$-Actin blots not intended for this experiment. These blots have now been replaced with the total ERK and $\beta$-Actin panels that were generated for this experiment. The corrected Fig. $2 \mathrm{~b}$ is shown here. However, the conclusion made from the experiment remains unaltered, and this correction has no bearing on the final outcome of the study. The inconvenience caused by this error is deeply regretted.

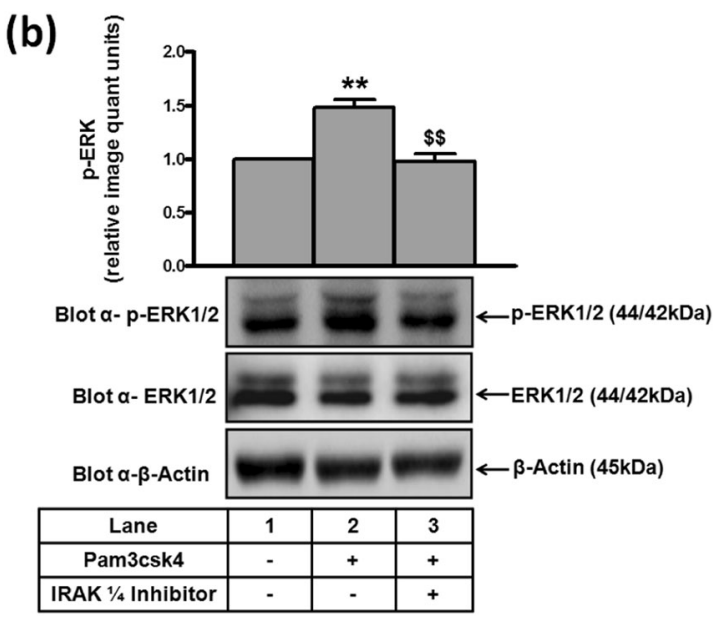

Fig. 2

${ }^{1}$ Pharmacology Division, CSIR-Central Drug Research Institute, B.S. 10/1, Sector 10, Sitapur Road, Jankipuram Extension, Lucknow 226031 Uttar Pradesh, India; ${ }^{2}$ Department of Transfusion Medicine and Blood Bank, King George's Medical University, Lucknow, Uttar Pradesh, India and ${ }^{3}$ Department of Pathology, King George's Medical University, Lucknow, Uttar Pradesh, India

Correspondence: Manoj K. Barthwal (manojbarthwal@cdri.res.in)

Published online: 11 September 2019 